\title{
Health-related quality of life among individuals with long-standing spinal cord injury: a comparative study of veterans and non-veterans
}

\author{
Soheil Saadat ${ }^{1}$, Masoud Javadi ${ }^{2}$, Baharak Sabet Divshali ${ }^{1}$, Amir Hussein Tavakoli ${ }^{3}$, Seyed Mohammad Ghodsi ${ }^{1,3}$, \\ Ali Montazeri ${ }^{4^{*}}$, Vafa Rahimi-Movaghar ${ }^{1,5^{*}}$
}

\begin{abstract}
Background: Spinal cord-injured (SCl) patients experience poor health-related quality of life (HRQOL) and they usually report lower HRQOL than the general population or population subgroups in Iran and elsewhere. The aim of this study was to compare HRQOL between veterans and non-veterans with $\mathrm{SCl}$ in Iran.

Methods: This was a cross-sectional study. HRQOL was measured using the 36-item Short Form Health Survey (SF36). Thirty-nine male veterans and 63 non-veteran males with SCl were included in the study. Regression analyses were applied to determine the variables affecting physical and mental health-related quality of life among the patients.

Results: The male veterans had a lower HRQOL than the non-veterans with $\mathrm{SCl}$. The differences were significant for all measures except for physical and social functioning. The greatest difference was observed for bodily pain ( $P$ $=0.001)$. The regression analysis results indicated that a longer time since injury was associated $(P=0.01)$ with better physical health-related quality of life $(P C S)$, while being a veteran $(P<0.001)$ and having a spinal lesion in the cervical region $(P=0.001)$ were associated with poorer $P C S$. Older age $(P<0.001)$ and higher education $(P=$ 0.01) were associated with better mental health-related quality of life (MCS), while being a veteran and having a spinal lesion in the cervical region $(P=0.02)$ were associated with poorer MCS.

Conclusion: The study findings showed that veterans with $\mathrm{SCl}$ experienced lower HRQOL than their non-veteran counterparts. A qualitative study is recommended to evaluate why HRQOL was lower in veterans than in nonveterans with $\mathrm{SCl}$ although veterans had higher incomes as a result of their pensions and increased access to equipment, and medications. To improve quality of life in both veterans and non-veterans with spinal cord injuries, policy changes or implementation of new interventions may be essential so that veterans could receive additional support (e.g. counseling, recreation therapy, vocational therapy, etc.) and non-veterans could meet their basic needs.
\end{abstract}

\section{Background}

Spinal cord injury (SCI) causes several health problems that negatively affect not only the patient's physical condition but all aspects of their lives including their goals and communications, and more importantly their health-related quality of life [1-6]. Active young males are the individuals who most commonly experience SCI,

\footnotetext{
* Correspondence: montazeri@acecr.ac.ir; v_rahimi@sina.tums.ac.ir

'Sina Trauma and Surgery Research Center, Tehran University of Medical Sciences, Tehran, Iran

${ }^{4}$ Department of Mental Health, Iranian Institute for Health Sciences Research, ACECR, Tehran, Iran
} ACECR, Tehran, Iran

and since this disability lasts for the rest of their lives [7], studying quality of life among this population is important.

Overall, the findings from several studies in the USA [8,9], Canada [10], Sweden [11] and Norway [12] using the 36-item Medical Outcomes Short Form Health Survey (SF-36) showed that HRQOL was low among SCI patients. These patients scored lower on almost all the SF-36 subscales or its component summary scores than either the general population or other population subgroups. As expected these patients scored lower on 
physical functioning as compared to other measures such as social functioning or mental health. The score for this particular domain was 26.6, 19.3, 23.9, 33.0, and 36.3 (out of 100) respectively corresponding to a difference of 25 to 60 points lower than the general population or normative data adjusted for age and gender [8-12]. On occasion, patients with SCI reported a better condition than the general population. For instance, a USA study showed that the mental component summary score of the SF-36 for SCI patients was higher than the normative value for the general population [8]. However, not only is quality of life low among veterans in general, but studies have also shown that they experience poorer HRQOL and overall health status than their non-veteran counterparts [13].

During the 1980-1988 Iran-Iraq war, the human cost to Iran included more than 200,000 lives lost and more than 400,000 persons injured [14], of whom 2012 were veterans with spinal cord injury. Currently, these veterans have access to several services including free healthcare such as bed sore management, wheelchair and rehabilitation services, insurance and special centers for annual physical examinations and laboratory tests, plus 800 US dollars per month to pay for a nurse and about 1200 US dollars monthly salary for their living expenses. In contrast, non-veterans do not have free insurance and only receive incomplete services from the State Welfare Organization of Iran, including a monthly salary of 50 US dollars, a wheelchair and limited rehabilitation services.

This study has two aims: to assess quality of life in male spinal cord injured veterans; and to compare health-related quality of life between veterans and nonveterans with SCI. To the best of our knowledge this is the first paper from Iran that reports on the topic.

\section{Methods}

\section{Design and data collection}

This was a cross-sectional study of quality of life among a convenient sample of SCI veterans and non-veteran SCI patients in Tehran, Iran. Veterans were approached during a recreational trip and were asked if they wished to take part in the study. Thirty-nine out of 41 veterans agreed to be interviewed. Additional information was extracted from their case records kept in the Janbazan (Veterans) Medical and Engineering Research Center. Non-veterans were selected from a consecutive sample of patients attending a neurosurgery outpatient department in Imam Hospital, affiliated to Tehran University of Medical Sciences, during the study period. Eightythree patients were approached and 63 agreed to take part. A face-to-face interview was arranged to collect data from both groups. Trained staff from the Janbazan (Veterans) Medical and Engineering Research Centre interviewed the veterans and trained staff from the Brain and Spinal Cord Injury Repair Research Center (BASIR) interviewed the non-veterans.

\section{Measures}

Health-related quality of life was measured using the SF36 questionnaire. The psychometric properties of the Iranian version of SF-36 are well documented [15]. The questionnaire comprises measures of physical functioning, role limitation due to physical problems (RP), bodily pain (BP), general health perceptions $(\mathrm{GH})$, vitality (VT), social functioning (SF), role limitation due to emotional problems (RE) and mental health (MH). These scales also provide two component summary scores: physical component summary (PCS) and mental component summary (MCS). Scores range from 0 to 100 with higher scores indicating better conditions [16,17]. This method of scoring (summated ratings) assumes that item or items belonging to each scale can be transformed or summed without standardization of scores or item weighting. We used this method to calculate scores.

For each individual, we also collected data on demographic factors, history since injury, level of injury, motor lesion, marital status at the time of injury and at the time of the study, and the number of children. It was thought that these variables might have significant positive or negative effects on health-related quality of life. For example, since patients might have suffered from infertility since their injury, this could affect their quality of life; hence we were interested in collecting data on the number of children.

\section{Statistical analysis}

In univariate analysis, the chi-square test (or Fisher's exact test and Yate's correction where necessary) was used to compare categorical variables. To compare the SF-36 scores between veterans and non-veterans, Student's t-test was performed. We estimated regression models to examine the association between individual characteristics and HRQOL. Separate linear regression analyses were carried out for the PCS and MCS, which were treated as dependent variables. For this purpose, the distributions of the PCS and the MCS scores were examined. There was slight negative skewness but this was less than one in both cases, allowing us to using the test. Age, time since injury, being a veteran, educational level, having a spouse, and SCI in the cervical region were included in the model as independent variables. Variables that failed to represent significant $P$ values $(P$ $<0.05)$ were excluded from the model using a backward elimination procedure.

\section{Ethics}

The study received approval from the Sina Trauma and Surgery Research Center, affiliated to Tehran University of Medical Sciences, and the Janbazan (Veterans) 
Medical and Engineering Research Center ethics committee. All patients gave their informed consent.

\section{Results}

Thirty-nine veteran and 63 non-veteran spinal cordinjured patients were included in the study. All the patients were male. Table 1 presents the characteristics of the study groups. The etiology of SCI in the veterans was shrapnel wounds (34.3\%), bullets $(22.9 \%)$, mines (5.7\%), falls $(8.6 \%)$, road traffic accidents $(2.9 \%)$ and other causes $(20.0 \%)$. In the non-veteran group, SCI resulted from road traffic crashes (49.2\%), falls (31.7\%), violence (12.7\%), sports injuries (3.2\%) and other causes (3.2\%).

The SF-36 scores for veterans and non-veterans are shown in Table 2 . There were significant differences between the two groups for all measures except for physical and social functioning, indicating that the veterans were experiencing poorer quality of life. All the veterans had complete SCI but the non-veterans had both complete and incomplete SCI. However, when the analysis was restricted to veterans and non-veterans who had suffered complete motor lesions, the results remained unchanged (Table 3).

Table 1 The characteristics of the study groups

\begin{tabular}{|c|c|c|c|c|}
\hline & & Veterans $(n=39)$ & Non-veterans $(n=63)$ & \\
\hline & & No. (\%) & No. (\%) & $\mathrm{P}$ \\
\hline \multicolumn{5}{|l|}{ Age (year) } \\
\hline & Mean (SD) & $45.2(5.3)$ & $34.3(8.3)$ & $<0.001$ \\
\hline & Range & $35-59$ & $19-57$ & \\
\hline \multirow[t]{4}{*}{ Educational level } & & & & $<0.001$ \\
\hline & Secondary school or less & $4(11.1)$ & $36(57.1)$ & \\
\hline & Diploma or college & $14(38.9)$ & $20(31.7)$ & \\
\hline & Higher & $18(50.0)$ & $7(11.1)$ & \\
\hline \multirow[t]{4}{*}{ Employment status } & & & & 0.151 \\
\hline & Employed & $12(34.3)$ & $12(19.0)$ & \\
\hline & Unemployed & $23(65.7)$ & $46(73.0)$ & \\
\hline & Retired & $0(0.0)$ & $5(8.0)$ & \\
\hline \multirow[t]{3}{*}{$\begin{array}{l}\text { Had spouse at the time of } \\
\text { injury }\end{array}$} & & & & $<0.001$ \\
\hline & Yes & $8(21.6)$ & $38(60.3)$ & \\
\hline & No & $29(78.4)$ & $25(39.7)$ & \\
\hline \multirow[t]{3}{*}{$\begin{array}{l}\text { Have spouse at the time of } \\
\text { study }\end{array}$} & & & & $<0.001$ \\
\hline & Yes & $30(88.2)$ & $34(54.0)$ & \\
\hline & No & $4(11.8)$ & $29(46.0)$ & \\
\hline \multirow[t]{5}{*}{ Number of children } & & & & 0.006 \\
\hline & 0 & $3(13.0)$ & $31(49.2)$ & \\
\hline & 1 & $13(56.5)$ & $11(17.5)$ & \\
\hline & 2 & $5(21.7)$ & $15(23.8)$ & \\
\hline & $\geq 3$ & $2(8.7)$ & $6(9.6)$ & \\
\hline \multicolumn{5}{|l|}{ Time since injury (year) } \\
\hline & Mean (SD) & $23.4(3.6)$ & $7.0(4.9)$ & $<0.001$ \\
\hline & Range & $12-29$ & $1-28$ & \\
\hline \multirow[t]{3}{*}{ Level of injury } & & & & 0.818 \\
\hline & Cervical & $22(56.4)$ & $37(58.7)$ & \\
\hline & Thoracic/Lumbar & 17 (43.6) & $26(41.3)$ & \\
\hline \multirow[t]{3}{*}{ Motor lesion } & & & & $<0.001$ \\
\hline & Complete & $39(100)$ & $29(46.0)$ & \\
\hline & Incomplete & $0(0.0)$ & $34(54.0)$ & \\
\hline
\end{tabular}


Table 2 The SF-36 scores in veteran versus non-veteran SCI patients

\begin{tabular}{llll}
\hline & Veterans $(\mathbf{n}=\mathbf{3 9})$ & Non-veterans $(\mathbf{n}=\mathbf{6 3})$ & $\mathbf{P}$ \\
\hline Physical functioning & Mean (SD) & Mean (SD) & 0.115 \\
\hline Role physical & $25.9(30.3)$ & $34.9(23.8)$ & 0.003 \\
\hline Bodily pain & $36.2(37.5)$ & $59.0(34.8)$ & 0.001 \\
\hline General health & $54.2(32.3)$ & $75.4(20.5)$ & 0.009 \\
\hline Social functioning & $52.8(20.9)$ & $62.9(17.0)$ & 0.145 \\
\hline Role emotional & $67.8(23.9)$ & $75.0(24.1)$ & 0.003 \\
\hline Vitality & $49.1(41.8)$ & $74.1(33.5)$ & 0.001 \\
\hline Mental health & $62.4(15.5)$ & $73.3(16.3)$ & 0.014 \\
\hline Physical component summary (PCS) & $67.8(16.8)$ & $76.0(15.5)$ & $<0.0001$ \\
\hline Mental component summary (MCS) & $42.4(19.5)$ & $58.1(14.8)$ & $<0.0001$ \\
\hline
\end{tabular}

Finally, regression analyses were applied to determine the effects of variables associated with PCS and MCS. Longer time since injury $(\mathrm{P}=0.01)$ was associated with a better PCS, while being a veteran $(\mathrm{P}<0.001)$ and having a spinal lesion in the cervical region $(P=0.001)$ were associated with a poorer PCS (Table 4). Older age $(\mathrm{P}<0.001)$ and higher education $(\mathrm{P}=0.01)$ were associated with a better MCS, while being a veteran and having a spinal lesion in the cervical region $(\mathrm{P}=0.02)$ were associated with a poorer MCS (Table 5).

\section{Discussion}

The study findings showed that male SCI veterans had lower HRQOL than male non-veteran SCI patients in Iran. Both the PCS and MCS and the SF-36 scores (except for physical and social functioning) were lower in veterans. Even comparison of the scores between veterans and the subset of non-veterans (those with complete motor lesions) yielded similar results. It is argued that complete motor lesions may lead to the occurrence of pressure ulcers and other complications by limiting the patient to bed or a wheelchair [18], so they might be associated with poorer HRQOL than patients with incomplete SCI $[5,19]$. It is argued that since many individuals with incomplete injuries also use wheelchairs and are at high risk for pressure ulcers thus the completeness of injury as a single reason could not justify these differences and there is need to find out more specific reasons and then pay attention to these reasons in order to improve quality of life in veterans. For example a recent study on pressure ulcers in veterans with spinal cord injuries found that diabetes and depressive symptoms were the most significant factors predicting pressure ulcers [20]. However, as indicated in Table 3, physical functioning was very low for both veterans (25.9) and non-veterans (27.6). This might be due to serious motor deficits in both groups. In contrast, the mean scores for role limitation due to physical problems (RP) were very different (36.2 in veterans vs. 60.1 in non-veterans). This means that veterans were more affected by their physical disabilities. Possible explanations for this might be related to differences in age or chronic conditions between the veterans and

Table 3 The SF-36 scores in veteran versus non-veteran suffering from complete motor lesions SCI

\begin{tabular}{llll}
\hline & Veterans $(\mathbf{n}=\mathbf{3 9})$ & $\begin{array}{l}\text { Complete motor lesions Non- } \\
\text { veterans }(\mathbf{n}=\mathbf{2 9})\end{array}$ & $\mathbf{P}$ \\
\hline Physical functioning & Mean (SD) & Mean (SD) & 0.78 \\
\hline Role physical & $25.9(30.3)$ & $27.6(20.4)$ & 0.009 \\
\hline Bodily pain & $36.2(37.5)$ & $60.1(33.7)$ & 0.001 \\
\hline General health & $54.2(32.3)$ & $77.4(20.5)$ & 0.002 \\
\hline Social functioning & $52.8(20.9)$ & $67.9(15.7)$ & 0.25 \\
\hline Role emotional & $67.8(23.9)$ & $75.0(26.3)$ & 0.007 \\
\hline Vitality & $49.1(41.8)$ & $74.7(32.9)$ & 0.004 \\
\hline Mental health & $62.4(15.5)$ & $73.4(14.7)$ & 0.02 \\
\hline Physical component summary (PCS) & $67.8(16.8)$ & $77.0(14.5)$ & $<0.0001$ \\
\hline Mental component summary (MCS) & $58.2(13.3)$ & 0.004 \\
\hline
\end{tabular}


Table 4 Regression analysis for physical component summary (PCS)*

\begin{tabular}{|c|c|c|c|c|c|}
\hline \multirow[t]{2}{*}{ Variables } & \multicolumn{2}{|c|}{ Unstandardized Coefficients } & \multicolumn{2}{|c|}{ Standardized Coefficients } & \multirow[b]{2}{*}{$P$} \\
\hline & Beta & Std. Error & Beta & $\mathrm{t}$ & \\
\hline $\begin{array}{l}\text { Non-veterans (versus } \\
\text { veterans) }\end{array}$ & 26.764 & 3.602 & 0.392 & 7.431 & $<0.001$ \\
\hline Time since injury & 7.695 & 2.910 & 0.206 & 2.645 & 0.01 \\
\hline $\begin{array}{l}\text { Lack of spinal injury in } \\
\text { cervical region }\end{array}$ & 10.515 & 3.074 & 0.283 & 3.421 & 0.001 \\
\hline
\end{tabular}

* Variables that failed to represent significant $P$ values $(P<0.05)$ were excluded from the model using a backward elimination procedure.

non-veterans. These possibilities should be investigated further in future studies.

Comparing role emotional (RE) in veterans and nonveterans revealed a significant difference between the two groups. It seems that male veterans with SCI had the more severe emotional disturbances in Iran. In contrast, two other published studies, the first from Iran concerning female veterans with SCI [21], and the second from the USA concerning veterans with SCI [22], showed that veterans scored higher on RE than on other subscales. A comparison of RE between Iranian and American veterans is not sound, and psychotherapy and other facilities might be much better for veterans in the USA, but the very low RE in our study subjects still needs more and deeper evaluation.

It has been shown that frequent mental distress and depressive symptoms are associated with poor selfreported health in individuals with spinal cord injury [23]. In addition, perceived stress was found to be higher in SCI veterans than non-veteran men with SCI. Another study found that male veterans with SCI had more hassles related to financial support, physical ability, health and healthcare in their daily lives; and they were more likely to be homeless, smokers, and heavy drinkers. The important issues acknowledged most frequently by veterans with SCI included physical abilities (endorsed by $70 \%$ ), their own health (62\%), medical care (56\%), money for extras (59\%), money for emergencies (57\%), and money for necessities (56\%) [24]. Thus, healthcare personnel providing services to veterans with SCI need to be aware of the hassles and chronic strains affecting their everyday lives. Indeed, comparison of stress and post-traumatic stress disorder (PTSD) between veterans and non-veterans might help to reveal additional reasons for the observed differences in health-related quality of life between these two groups. Unfortunately, we did not collect data on such variables. This should be considered for similar studies in the future.

Higher expectation of life quality among veterans may be another explanation for the lower HRQOL among male veteran SCI patients. In fact, although SCI veterans enjoyed financial support and increased health care access, their higher expectations might have resulted in lower HRQOL than among the non-veteran SCI patients. To explain further, it should be noted that many Iranian veterans with SCI took part in the IranIraq war voluntarily and intentionally, and expected that at the end of the war they would have an ideal society. They were ready to be injured or even to die to establish an ideal country. They self-sacrificed their health, but when they came back to their home towns after their injuries or 8 years of war, they were confronted with a society worse than they expected; a society with many broken values. Thus, their evaluation of their new life was now very different from that of a patient who, for instance, had suffered SCI following a road accident and consequently reported a lower quality of life. We believe this explanation is highly consistent with the quality of life definition offered by the World Health Organization: 'an individual's perception of his/her position in life in the context of the culture and value system in which he/she lives, and in relation to his/her goals, expectations, standards, and concerns' [25]. There is evidence

Table 5 Regression analysis for mental component summary (MCS)*

\begin{tabular}{lllll}
\hline Variables & Unstandardized Coefficients & \multicolumn{2}{l}{ Standardized Coefficients } \\
\hline & Beta & Std. Error & Beta & t \\
\hline $\begin{array}{l}\text { Non-veterans (versus } \\
\text { veterans) }\end{array}$ & 26.703 & 3.258 & 0.299 & 8.197 \\
\hline Age & 0.857 & .144 & 0.461 & 5.967 \\
\hline $\begin{array}{l}\text { Educational level } \\
\text { Lack of spinal injury in } \\
\text { cervical region }\end{array}$ & 5.310 & 2.111 & 0.145 & 2.515 \\
\hline
\end{tabular}

* Variables that failed to represent significant $P$ values $(P<0.05)$ were excluded from the model using a backward elimination procedure. 
that for example expectations regarding aging could influence physical and mental health. A recent study reported that a positive expectation about ageing was associated with better physical and mental health, after adjusting for age, gender and education [26]. However, this hypothesis is the authors' own thoughts and merits further investigation in future studies of HRQOL among injured veterans in Iran and perhaps elsewhere.

We used a well-known instrument (the SF-36) to measure quality of life in individuals with SCI. This is a generic measure, and it would seem much better to assess quality of life in this population by more specific questionnaires in addition to such instruments. For example, Luther et al. developed an 8-item SCI-specific physical functioning scale for veterans that showed strong psychometric properties [27]. It is argued that little research has been conducted specifically to ascertain perception of quality of life among people with spinal cord injuries [28]. However, as noted in a recent review of the literature, much remains to be discovered about SCI individuals in terms of their functional health, well-being, and the relative burden of the disease [29]. The effect of physical disability or illness cannot be fully understood without considering both the specific areas of functioning affected by the physical condition and the aspects of health-related quality of life that are of particular importance to the individual [30].

This study had several limitations. The major limitations were the small sample size and the fact that we did not collect data on the patients' chronic illnesses and common complications. There is evidence that chronic illnesses have a substantial effect on healthrelated quality of life for persons with SCI [23,31,32]. In addition, the veterans were much older than the nonveterans so they were probably experiencing higher rates of diabetes, renal disease, chronic pulmonary diseases and other chronic illnesses, or pressure ulcers, than the non-veteran group. Time since injury also was longer for the veterans. Thus, the findings from this study might not be generalized, although two recent studies have shown no relationships between time since injury, age and quality of life among individuals with spinal cord injuries $[2,3]$.

\section{Conclusion}

The study findings showed that veterans with SCI experienced lower HRQOL than their non-veteran counterparts. A qualitative study is recommended to evaluate why HRQOL was lower in veterans than in non-veterans with SCI although veterans had higher incomes as a result of their pensions and increased access to equipment, and medications. To improve quality of life in both veterans and non-veterans with spinal cord injuries, policy changes or implementation of new interventions may be essential so that veterans could receive additional support (e.g. counseling, recreation therapy, vocational therapy, etc.) and non-veterans could meet their basic needs.

\section{Abbreviations}

SCI: Spinal cord injury; HRQOL: Health related quality of life; PCS: Physical component summary; MCS: Mental component summary; SF-36: 36-item Short Form Health Survey questionnaire; RP: role limitation due to physical problems; RE: role limitation due to emotional problems

\section{Acknowledgements}

This study was approved in three centers. The centers and grant numbers were as follows: Brain and Spinal Cord Injury Repair Research Center (BASIR)700/55/1680; Sina Trauma and Surgery Research Center-73; Janbazan

Medical and Engineering Research Center-86p/103. The date of agreement was June 10, 2008. No budget was received from BASIR. We would appreciate all members of three centers and the SCl patients for their cooperation in this study. The authors thank Miss Mariam Ghahramani for extracting patients' case records and Mrs. Bita Pourmand for editing the manuscript.

\section{Author details}

${ }^{1}$ Sina Trauma and Surgery Research Center, Tehran University of Medical Sciences, Tehran, Iran. ${ }^{2} J a n b a z a n$ Medical and Engineering Research Center (JMERC), Tehran, Iran. ${ }^{3}$ Brain and Spinal Cord Injury Repair Research Center (BASIR), Tehran University of Medical Sciences, Tehran, Iran. ${ }^{4}$ Department of Mental Health, Iranian Institute for Health Sciences Research, ACECR, Tehran, Iran. ${ }^{5}$ Research Centre for Neural Repair, Tehran University, Tehran, Iran.

\section{Authors' contributions}

SS contributed to the data analysis and writing the first draft. BSD wrote the proposal. AHT, MJ, and SMG confirmed proposal and collected the SF-36 data and took part in the study. AM helped as a consultant in all parts of the study, rechecked the data analysis and revised the final manuscript. VRM was the principal investigator and performed quality control on patients' case records, was responsible in all parts of the study, wrote draft and revised the manuscript. All authors read and approved the final manuscript.

\section{Competing interests}

The authors declare that they have no competing interests.

Received: 3 June 2009

Accepted: 5 January 2010 Published: 5 January 2010

\section{References}

1. Kreuter M, Siosteen A, Erkholm B, Bystrom U, Brown DJ: Health and quality of life of persons with spinal cord lesion in Australia and Sweden. Spinal Cord 2005, 43:123-129.

2. Barker RN, Kendall MD, Amsters DI, Pershouse KJ, Haines TP, Kuipers P: The relationship between quality of life and disability across the lifespan for people with spinal cord injury. Spinal Cord 2009, 47:149-155.

3. Middleton J, Tran Y, Craig A: Relationship between quality of life and selfefficacy in persons with spinal cord injuries. Arch Phys Med Rehabil 2007, 88:1643-1648.

4. Blanes L, Carmagnani MI, Ferreira LM: Quality of life and self-esteem of persons with paraplegia living in São Paulo, Brazil. Qual Life Res 2009, 18:15-21.

5. Hu Y, Mak JN, Wong YW, Leong JC, Luk KD: Quality of life of traumatic spinal cord injured patients in Hong Kong. J Rehabil Med 2008, 40:126131.

6. Lidal IB, Veenstra M, Hjeltnes $N$, Biering-Sørensen F: Health-related quality of life in persons with long-standing spinal cord injury. Spinal Cord 2008, 46:710-715.

7. Franceschini M, Clemente B.D, Rampello A, Nora M, Spizzichino L: Longitudinal outcome 6 years after spinal cord injury. Spinal cord 2003, 41:280-285.

8. Forchheimer M, McAweeney M, Tate DG: Use of the SF-36 among persons with spinal cord injury. Am J Phys Med Rehabil 2004, 83:390-395. 
9. Lucke KT, Coccia H, Goode JS, Lucke JF: Quality of life in spinal cord injured individuals and their caregivers during the initial 6 moths following rehabilitation. Qual Life Res 2004, 13:97-110.

10. Leduc BE, Lepage $Y$ : Health-related quality of life after spinal cord injury. Disabil Rehabil 2002, 24:196-202.

11. Elfstrom M, Ryden A, Kreuter M, Taft C, Sullivan M: Relations between coping strategies and health-related quality of life in patients with spinal cord lesion. J Rehabil Med 2005, 37:9-16.

12. Lidal IB, Veenstra M, Hjeltnes N, Biering-Sorensen F: Health-related quality of life in person with long-standing spinal cord injury. Spinal Cord 2008, 46:710-715.

13. Kazis LE, Miller DR, Clark J, Skinner K, Lee A, Rogers W, Spiro A, Payne S, Fincke $G$, Selim A, Linzer M: Health-related quality of life in patients served by the Department of Veterans Affairs. Arch Intern Med 1998 158:626-632.

14. Mousavi B, Soroush MR, Montazeri A: Quality of life in chemical warfare survivors with ophthalmologic injuries: the first results form Iran Chemical Warfare Victims Health Assessment Study. Health and Quality of Life Outcomes 2009, 7:2.

15. Montazeri A, Goshtasebi A, Vahdaninia M, Gandek B: The Short Form Health Survey (SF-36): translation and validation study of the Iranian version. Qual Life Re 2005, 14:875-882.

16. Ware JE, Sherbourne CD: The MOS 36-item short-form health survey (SF36). I. Conceptual framework and item selection. Med Care 1992, 30:473483.

17. Ware JE, Kosinski M, Keller SK: SF-36 Physical and Mental Health Summary Scales: A User's Manual Boston, MA: The Health Institute 1994.

18. Davatgaran K, Habibi R, Rasouli MR, Saadat S, Moghadam M, Vaccaro AR, Rahimi-Movaghar $\mathrm{V}$ : Factors associated with pressure ulcers in patients with complete or sensory-only preserved spinal cord injury: is there any difference between traumatic and nontraumatic causes?. J Neurosurg Spine 2009, 11:438-443.

19. Jain NB, Sullivan M, Kazis LE, Tun CG, Garshick E: Factors associated with health-related quality of life in chronic spinal cord injury. Am J Phys Med Rehabil 2007, 86:387-396.

20. Smith BM, Guihan M, LaVela SL, Garber SL: Factors predicting pressure ulcers in veterans with spinal cord injuries. Am J Phys Med Rehabil 2008, 87:750-757.

21. Mousavi B, Montazeri A, Soroush MR: Quality of life in spinal cord injured female veterans. Payesh 2008, 7:75-81, [Persian]..

22. Andresen EM, Fouts BS, Romeis JC, Brownson CA: Performance of healthrelated quality-of-life instruments in a spinal cord injured population. Phys Med Rehabil 1999, 80:877-884.

23. Smith BM, LaVela SL, Weaver FM: Health-related quality of life for veterans with spinal cord injury. Spinal Cord 2008, 46:507-512.

24. Rintala DH, Robinson-Whelen S, Matamoros R: Subjective stress in male veterans with spinal cord injury. J Rehabil Res Dev 2005, 42:291-304.

25. WHOQOL Group: Study protocol for the World Health Organization project to develop a Quality of Life assessment instrument (WHOQOL). Qual Life Res 1993, 2:153-159.

26. Kim SH: Older people's expectations regarding ageing, health-promoting behaviour and health status. J Adv Nurs 2009, 65:84-91.

27. Luther SL, Kromrey J, Powell-Cope G, Rosenberg D, Nelson A, Ahmed S, Quigley P: A pilot study to modify the SF-36V physical functioning scale for use with veterans with spinal cord injury. Arch Phys Med Rehabil 2006, 87:1059-1066.

28. Hammell KW: Exploring quality of life following high spinal cord injury: a review and critique. Spinal Cord 2004, 42:491-502.

29. $\mathrm{Ku} \mathrm{JH}$ : Health-related quality of life in patients with spinal cord injury: review of the short form 36-health questionnaire survey. Yonsei Med J 2007, 48:360-370.

30. Tate $D G$, riley BB, Perna R, Roller S: Quality of life issues among women with physical disabilities or breast cancer. Arch Phys Med Rehabil 1997, 78: S18-S25.

31. Singh JA, Sloan J: Higher comorbidity, poor functional status and higher health care utilization in veterans with prevalent total knee arthroplasty or total hip arthroplasty. Clin Rheumatol 2009, 28:1025-1033.

32. Singh JA: Effect of comorbidity on quality of life of male veterans with prevalent primary total knee arthroplasty. Clin Rheumatol 2009, 28:10831089.

\section{Pre-publication history}

The pre-publication history for this paper can be accessed here:http://www. biomedcentral.com/1471-2458/10/6/prepub

doi:10.1186/1471-2458-10-6

Cite this article as: Saadat et al:: Health-related quality of life among individuals with long-standing spinal cord injury: a comparative study of veterans and non-veterans. BMC Public Health 2010 10:6.

\section{Publish with Bio Med Central and every scientist can read your work free of charge}

"BioMed Central will be the most significant development for disseminating the results of biomedical research in our lifetime. "

Sir Paul Nurse, Cancer Research UK

Your research papers will be:

- available free of charge to the entire biomedical community

- peer reviewed and published immediately upon acceptance

- cited in PubMed and archived on PubMed Central

- yours - you keep the copyright
BioMedcentral 